\title{
NUMERICAL ANALYSIS OF DOOR CLOSING VELOCITY FOR A PASSENGER CAR
}

\author{
Mr. Navalkumar Kavthekar ${ }^{1}$ and Dr. Prof. Avinash Badadhe ${ }^{2}$ \\ ${ }^{1}$ Department of Mechanical Engineering, Rajarshi Shahu College of Engineering, \\ Pune University, Tathawade.
}

\begin{abstract}
In the automobile industry, the term build quality is a quality which is perceived by customer by his senses viz. sight, sound, touch and smell. Door closing effort gives an indication of how good or bad the vehicle is engineered. The purpose of this paper is to propose modification in the door system which helps in reduction of door closing velocity. In this paper, parameters like hinge friction, hinge axis inclination, sealing, latch and air bind effect are analysed which affects door closing effort. A mathematical model is prepared to evaluate door closing velocity through calculating energy contribution by each parameter. Door closing velocity is calculated for the existing model and to improve the existing scenario, design modifications are proposed. These design modifications after implementation have shown reduction in door closing velocity by $22.8 \%$. Physical validation is done and results were found in line with the theoretical calculations.
\end{abstract}

\section{KEYWORDS}

Door closing velocity, Perceived Quality, Hinge axis, inward and outward angle, forward and rearward angle, Compression Load Deflection, Latching resistance and check strap resistance \& Energy

\section{INTRODUCTION}

In the automobile industry, the door closing effort spells out the engineering and quality of the vehicle. After the visual impact a vehicle has on the customer, the doors are most likely the very first part of the vehicle he/she comes into contact with, to enter and exit the vehicle. One of the customer's very first impressions about the quality of the car is given by the behaviour of the doors when opening and closing, the swinging velocity and the energy that are required to obtain a full latching, and the sound that the door makes when closed by the user. Moreover, an incomplete closure of the door or an excessive closing velocity required to fully latch might give rise to safety issues like high pressure on ear drums or unpleasant sound during closure [1]. Car manufacturers have to deal with many different problems, often related to government regulations, standards and safety issues. Another main factor leading to the car company's choice is customer's perception and impression on the quality of the product to be sold. Door closing performance is strictly related to this last aspect. The purpose of this project is to evaluate the consequences, in terms of door closing effort, analysing all the differences and design consideration in the door closing process. This will help us to understand which actions need to be taken, in case the performance deviates from the given target. The term closing effort can be intended as the total energy needed to fully latch the door, but the greatest focus is put on the effort that the customer needs to put in order to shut the door. The best way to analyse is to have the values of the parameters pertaining to door closing effort of all competitors' benchmark values in order to be able to directly compare [5]. Once the values of the energy contribution are 
known from engineering calculations or from physical tests, it is possible to understand on what parameters it is necessary to work, either to lower the value of the energy sink during closure or to increase the amount of energy given by the factors that help the user in closing the door. However, the precise prediction of the door closing energy has remained somewhat beyond description. Consequently, as a quality issue receiving the most complaints from customers, the excessive automotive door closing energy turns into an expected and vital problem yet to be solved. In almost all OEM's (Original Equipment manufacturer) door closing velocity is measured which can be equated to total energy consumed by door for closing. Many studies have been made on automotive door closing energy.

Y. Nagayama et al. has emphasized on the phenomenon called as air tightness. According to author air tight integrity hinders the door closing and increase the effort. The pressure increase due to air tight also causes passenger ear drum to temporary pressurize. Pressure rise due to each parameter like Capacity of passenger Compartment, speed at which door is shut; area of air vent hole, Inertia of the door and projected area of door are plotted. Air extraction valve is designed to maintain pressure below human ear drum tolerable limit $\&$ to reduce door closing effort. Author has concluded the larger the opening area larger, lesser will be the pressure rise in cabin which will eventually reduce the door closing effort. But larger opening area will have an effect on EBHS (Equivalent Body Hole size) value of the product which will lead to NVH (Noise, vibration and Harshness) and BSR (Buzz squeak and rattle) issues. Experimental approach and with help regression analysis empirical formulas are derive to measure magnitude of minimum door velocity and rise in cabin pressure [1].

Raviraj Nayak et al. Adams simulating model has been prepared which includes all components that contributes to the door closing effort. Author has described two methods for analysing one is to apply certain door closing velocity to door at full open condition and plot a graph of decrease in Kinetic energy of door during closing motion, as it overcomes the resistance of check link, air bind, seal and latch. The other way he mentioned was to perform a quasi-static analysis, wherein door is opened and closed at constant angular velocity and force is tracked at door handle. In these methodologies we have to rely on simulation which is very time consuming and a specialized man power is required for modelling. For each geometry change we have to re run the simulation which will be time consuming [2].

Vitor de Uzeda Sandrini et al. In Hummer case study, only door seals contributing factors are focused and detail evaluation of other factors are not done. An approximation method in each factor would have helped rather than only modifying the CLD (Compression Load Deflection) value of seal which resulted in another problem of wind noise in cabin due to poor sealing. However this problem was later solved by adding a stuff inside, which shows a possibility of increasing CLD with stuff material inside [3].

Jing Li et al has described a mathematical model for predicting the side door closing effort Velocity required for the door from a small open position when the check-link ceases to function are studied in this paper The door closing effort prediction model is implemented using visual basic in EXCEL. Energy due to air bind is due to additional air pushed by closing door inside the cabin which creates a pressure rise in the vehicle. Torque at hinge axis increases due to pressure rise. The seal stiffness of each segment is represented by a spring connecting a point on the door seal line and a corresponding point on the body seal line. Hinge frictional force and reaction due to door mass centre which creates moment during closing was considered and Torque of this parameter was evaluated and energy due to friction and Inertia was estimated. Addition to this latch energy was estimated as latch forces and distance travelled by pawl along the striker was known. The contribution of check link is ignored in this paper. Calibration methodology for hinge 
model, the latch model, the seal compression model, and the air bind model was used to reduce error with help of measured values [4].

Fernando Pereira et al. has discussed all the contribution factors in door closing effort which will help designers to design door at concept stage in the development period for minimizing door closing effort. Potential energy due to hinge axis inclination is not considered in detail. Moreover, for check strap only the resistance contributing in opposite direction is considered. Also for each crevice, the resistance, which is variable, it is assumed to be constant in this paper. Only initial estimation of door closing velocity can be predicted [5].

\section{FACTORS AFFECTING DOOR CLOSING VELOCITY}

The major contributors in door closing effort are as below:

\subsection{Hinge friction}

Frictional force between hinge pin and two leaves hinder door closing and contribute in door closing effort [4]. Hinge operating torque is specified by the hinge designer to meet component level functional \& legislative requirements.

\subsection{Hinge axis inclination, door weight \& Centre of Gravity}

Inertial moment is obtained by experimentation and calculation. A larger distance between the centre of gravity and hinge axis can improve closing velocity in a door system, where the centre of gravity varies depending on the type of door-module and motor position. To satisfy the glass up \& down performance and the durability of door-module at the same time, the type of doormodule and motor position should be determined carefully through mathematical model analysis and experimentation. During the door closing process, the dip angle of the hinge axis directly impacts the movement of the centre of gravity of the vehicle door, which bears an important role in deciding whether the door weight would provide or consume the door closing energy. To reduce the door closing effort, the door hinge axis is typically tilted towards the inside of the vehicle to take the advantage of gravity and to overcome the significant resistance from the seal, latch, and air-bind to fully shut the door. Hinge axis is relative to energy required to close the door with more than the Minimum closing velocity. Hinge axis inclination when viewed from front view has a stronger effect on door closing than hinge axis inclination viewed from side view.

\subsection{Check strap System}

Check link is a device controlling the closing and opening of the door, and usually has three tap positions. The force required to overcome its door intended position hinders the door closing force. Factors affecting check link performance are: Radius of slide, Radius of edge, hardness of rubber and arm thickness.

\subsection{Latching force}

If the latch striker stays on a certain tap position, the door needs an external force to jump out of it, and then, the elastic potential energy stored in the latch striker spring can automatically push the door. 


\subsection{Door Seal force}

Resistance to the door closing depends on the nonlinear elastic compression load deflection (CLD) resistance, which are determined by the fractional volume decrease curve that is CLD curve of seal. The compressive deformation characteristics of the seal play an important role in seal energy consumption. The seal is compressed gradually during the door closing process, so the seal deformation is continuous. The seal system is discredited into tiny segments with certain length, and the total energy consumption can be calculated by adding the energy consumed by each segment together.

\subsection{Air binding effect}

A temporary pressure increase within the passenger compartment with all the windows glasses closed is called the air binding effect. The area $A_{1}$ is the fixed area for air release and $A_{2}$ is the area that the door closing perimeter makes with the auto body side. During the door closing process, the air is squeezed into the passenger compartment and released through $A_{1}$ and $A_{2}$ with the application of the law of mass conservation.

\section{TARGET SETTING}

A detail bench marking was done in this case and target for door closing for upcoming vehicle was set.

Table 1. Benchmark values of door closing velocity

\begin{tabular}{|c|l|l|l|}
\hline Sr. No. & Make & Model & $\begin{array}{l}\text { Front door closing velocity } \\
\text { in } \mathbf{~} / \mathbf{s}\end{array}$ \\
\hline 1 & Benchmark No. 1 & Hatchback & 0.79 \\
\hline 2 & Benchmark No. 2 & Hatchback & 0.84 \\
\hline 3 & Benchmark No. 3 & Sedan & 0.8 \\
\hline 4 & Benchmark No. 4 & Sedan & 0.98 \\
\hline 5 & Benchmark No. 5 & Sedan & 1.03 \\
\hline 6 & Model 1 Before modification & Hatchback & $1.1-1.3$ \\
\hline
\end{tabular}

Table 1 shows benchmark measured values of Door closing velocities of all competitors vehicle. Model no. 1 velocity was too high and the problem of door shutting hard subjective feeling was identified. Benchmark values were referred for target setting. Considering other aspects like carry over parts strategy, Geometric / design (styling) constraints \& cost impact were also equally important. Finally the target given by PAT (Performance attribute target) team was $0.9 \mathrm{~m} / \mathrm{s}$. Figure 1 shows the graphical representation of benchmark comparison. 


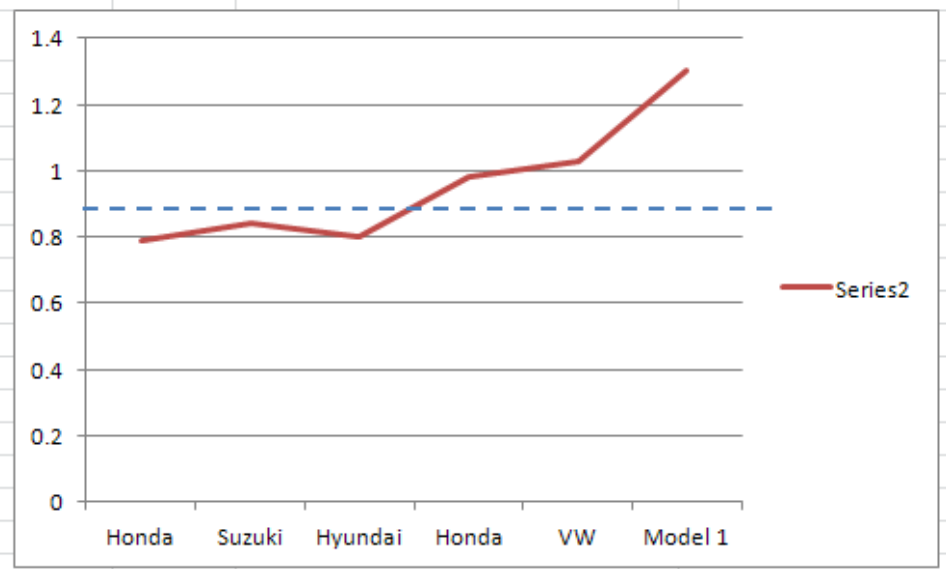

Figure 1. Benchmark comparison with Existing model

\section{AnAlytical APProach}

\subsection{Hinge frictional force " $F_{H F}$ "}

Hinge torque value is specified in drawing. Hinge Torque: $1.2 \mathrm{Nm} \pm 10 \%$ Static to dynamic friction ratio : $0.8 *$ Hinge torque $($ Std. $)=0.96 \mathrm{~N}-\mathrm{m}$

Therefore, Hinge Friction force can be written as:

$$
F_{H F}=\frac{\text { static to dynamic frictional Torque }}{l} * 1000 * 2
$$

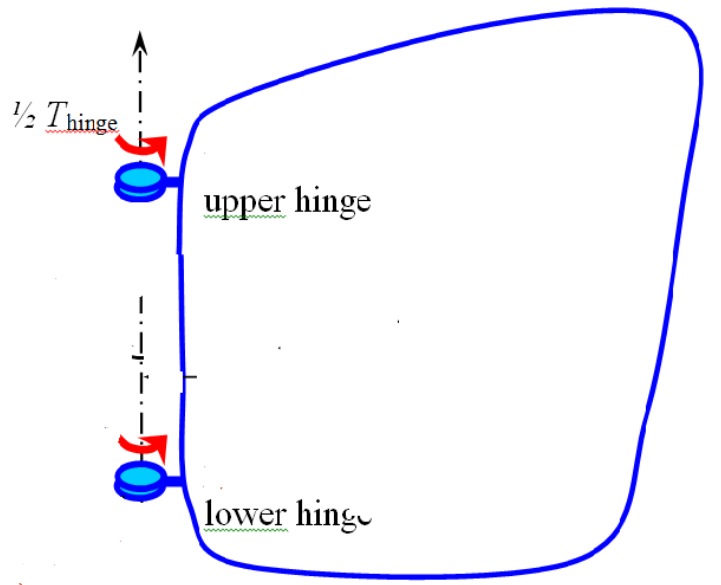

Figure 2. [4] Frictional resistance in Upper and Lower Hinges

Figure 2 shows the frictional forces due to hinge torque. Where $l=$ Distance of Outer Handle from hinge $(\mathrm{mm})$, Here in model $l=787.08 \mathrm{~mm}$ (measured value)

Therefore Hinge Frictional Force $\left(F_{H F}\right)=2.44 \mathrm{~N}$.

Hinge friction is assumed constant at all angles of door

4.2 Force due to Hinge axis inclination, door weight \& C.G. 


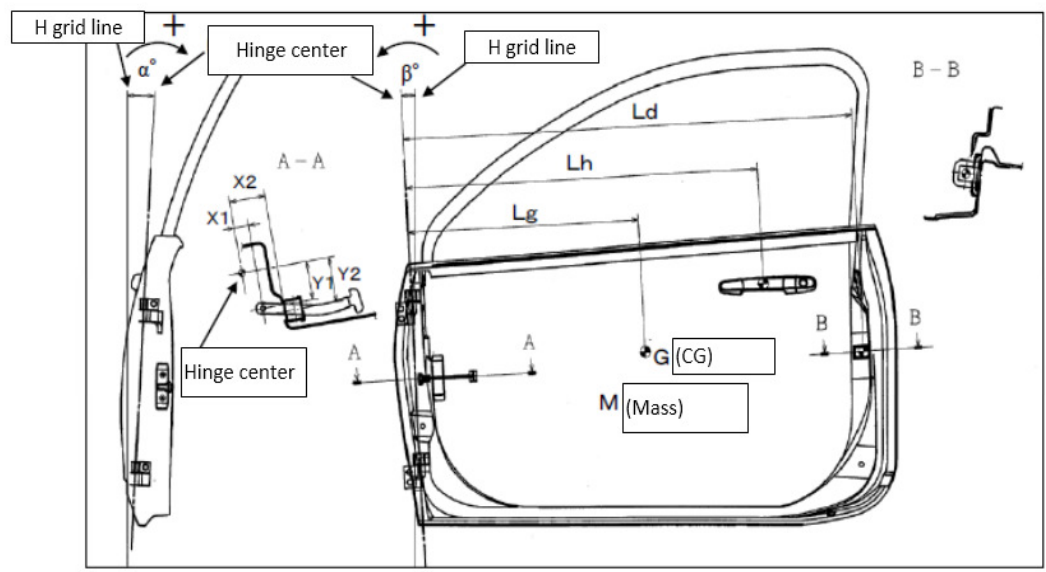

Figure 3. Schematic representation of Complete Door with all trim parts

Figure 3 shows schematic representation of complete door with all trim parts. The hinge centreline can be inclined as viewed in front and on the side. As viewed in front, the finger centre line is desired to be inclined on the car line. With the hinge centre line is inclined, doors will have a self-closing force generated when opened and closed. As a result, it is necessary to increase the force which the link will check.

\subsubsection{Forward/ Rearward angle " $\beta$ "}

The hinge axis, when viewed from dead side view, is inclined at an angle with respect to $\mathrm{Z}$ axis as shown in the above figure. The angle can be calculated from below equation.

By substituting the above values the forward / rearward angle

$\beta=\tan ^{-1} \frac{(X 1-X 2)}{(Z 1-Z 2)} * \frac{180}{\pi}$

$\beta=-1.61^{\circ}$ where $\mathrm{X} 1, \mathrm{Y}_{1}, \mathrm{Z}_{1}=$ Upper hinge coordinates; $\mathrm{X}_{2}, \mathrm{Y}_{2}, \mathrm{Z}_{2}=$ Lower hinge coordinates The negative sign indicates that the axis is inclined forward when viewed from dead side view

\subsubsection{Inward / Outward angle " $\alpha$ "}

The hinge axis when viewed from front view is inclined at an angle with respect to $\mathrm{Z}$ axis as shown in above figure. The angle can be calculated from below equation. By substituting the above values the forward / rearward angle

$\alpha=\tan ^{-1} \frac{(Y 1 \quad Y 2)}{(Z 1-Z 2)} * \frac{180}{\pi}$

$\alpha=2.07$

The sign indicates that the axis is inclined inward when viewed from front view.

\subsubsection{Force due to Inward Hinge axis angle "Fi"}


When the door is opened at an angle " $\theta$ ", Force " $F_{i}$ " at that instance can be written as below equation

$F i=\frac{L g}{L d} * W * \sin (180+\alpha) * \sin \theta * 9.81$

Distance from C.G. to hinge axis; $L d=$ Distance from C.G. to Outer door handle;

$\mathrm{W}=$ Weight. Figure 4 shows the individual inward tilt force vs. door closing velocity

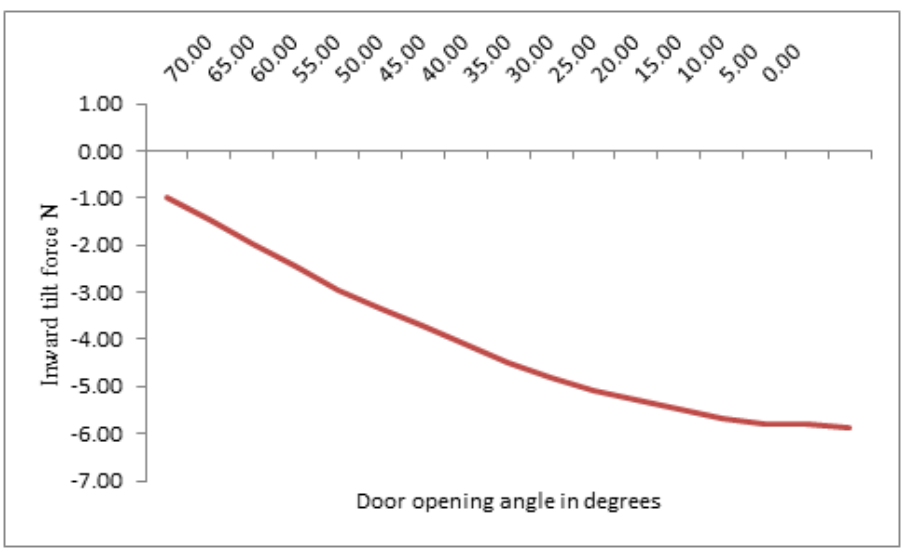

Figure 4. Inward tilt forces Vs. Door Opening angle

\subsubsection{Force due to Forward Hinge axis angle " $F_{f}$ "}

When the door is opened at an angle " $\theta$ " Force " $F_{\mathrm{f}}$ " at that instance can be written as below equation

$F f=\frac{L g}{L d} * W * \sin (100+\alpha) * \sin \theta * 9.81$

Figure 5 shows the individual forward tilt force vs. door closing velocity

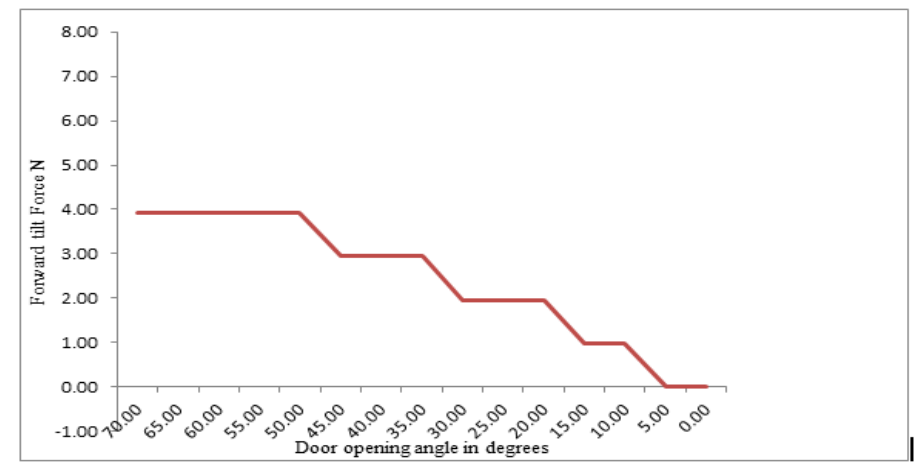

Figure 5. Forward tilt force Vs. Door Opening angle 


\subsubsection{Total force due to hinge axis inclination and frictional force is " $F t$ "}

Therefore Total force due to hinge axis inclination is summation of above three forces

$\mathrm{Ft}=\mathrm{Fhf}+\mathrm{Fi}+\mathrm{Fr}$

Figure 6 shows the Total force due to hinge axis inclination vs. door closing velocity

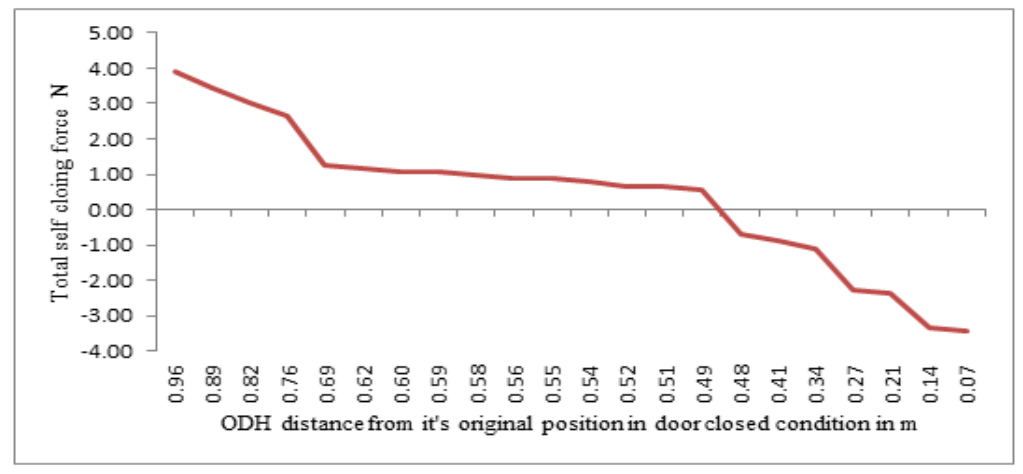

Figure 6. Total self-closing forces due to hinge inclination Vs. Door Opening distance from its original

\subsubsection{Energy due to self-closing force" $\mathrm{E}_{\mathrm{SCF}}$ "}

In this paper, the basic aim is to estimate the energy consumed by each parameter which contributes to the door closing effort. To calculate this energy, the distance travelled where the force is applied by user also needs to be calculated or to be evaluated from CAD as energy is product of force required and distance covered. Energy due to self-closing force can be given by below equation.

$\mathrm{E}_{\mathrm{SCF}}=\mathrm{Ft} *$ Distance travelled at Outer door handle location

Therefore total energy due to hinge axis inclination and hinge frictional is the area under the graph $\mathbf{=} \mathbf{- 0 . 0 7}$ Joules.

Negative sign in the energy value indicates that the behaviour of the door is self-closing while the positive sign indicates that the door needs additional energy for closing. Basically here estimation of energy one from full open condition and other from intermediate is also possible.

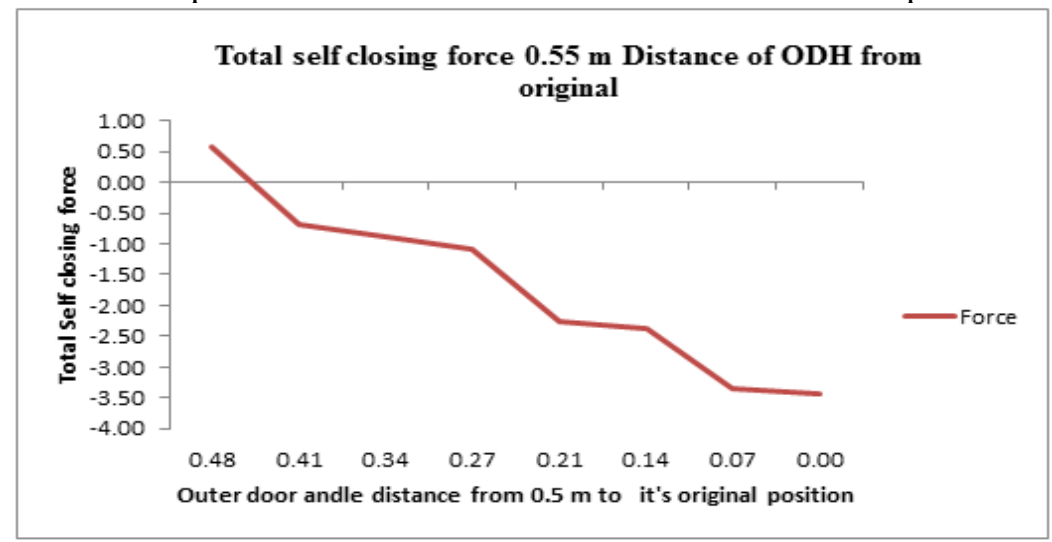

Figure 7. Total self-closing forces due to hinge axis vs. Door Opening distance from $0.55 \mathrm{mts}$ 
Most of the OEM calculates energy just after the last check point while closing and that is the ideal scenario or case used by all customers. The PAT (Performance attribute team) team has also considers the same thing and input was given on the basis of the same. In this case the distance of Outer Door Handle (ODH) is $0.55 \mathrm{~m}$ from its original position. Figure 7 shows force required from 0.55 meter distance of ODH from its original position.

\subsection{Forces due check strap System resistance}
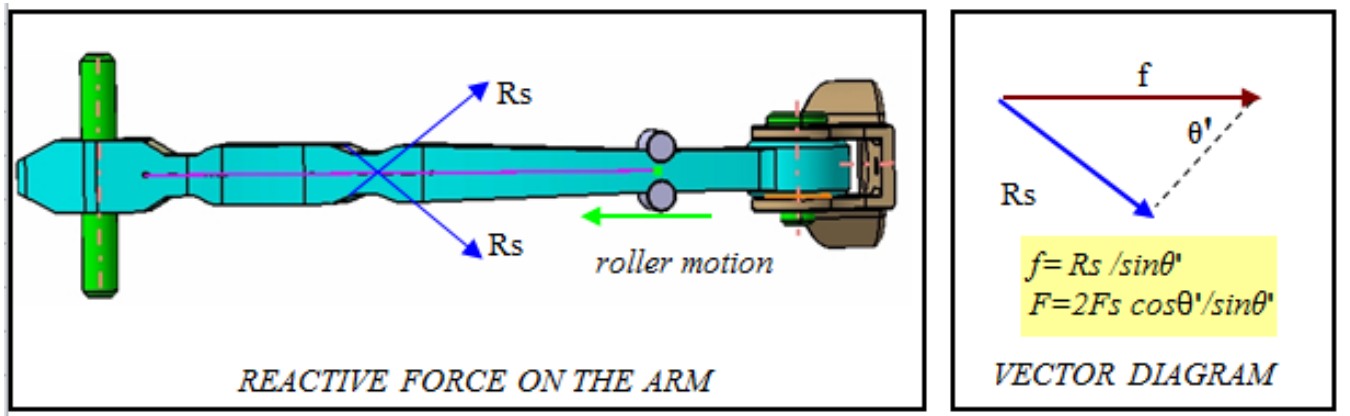

Figure 8. Forces on the Check arm

Figure 8 shows forces on check arm and vector diagram

$\mathrm{Fs}=\mathrm{k}(\mathrm{dp}+\mathrm{d})(\cos \theta+\mu \sin \theta)$

$\mathrm{Fs}=$ spring force acting on the roller; $\mathrm{F}=2 . \mathrm{Fs} \cos \theta / \sin \theta$

Therefore, $\mathrm{F}=2 . \mathrm{k}(\mathrm{dp}+\mathrm{d})(\cos \theta+\mu \sin \theta) / \sin \theta$

Where, $d p=$ Rubber compression; $d=$ Length of rubber after compression; $K=$ stiffness of rubber, $\mathrm{F}=$ check strap resistance

Door effort (at handle) due to check arm is the force by the check arm is due to the compression of the spring and the inclination of the check arm surface on which the roller moves. Figure 9 shows Schematic representations of force at ODH and at check strap

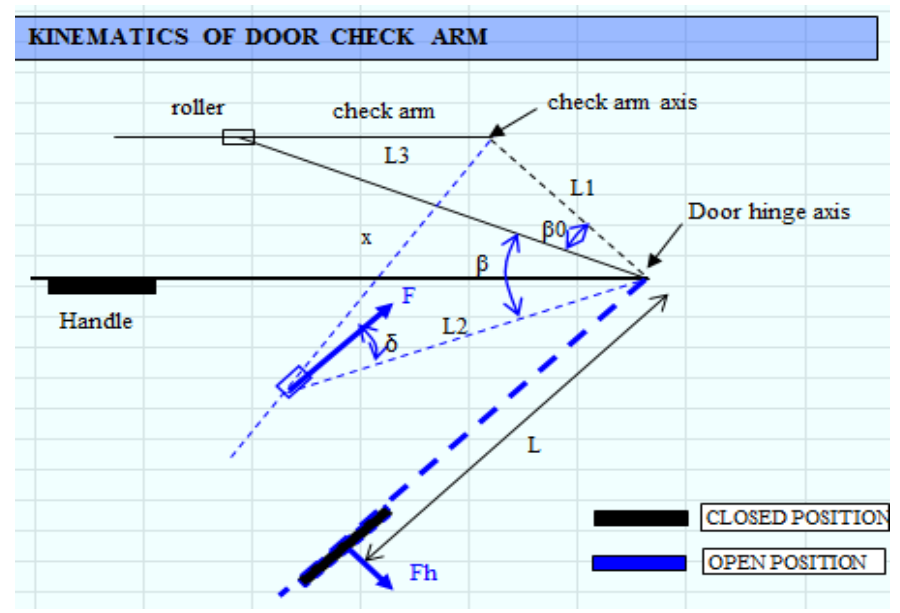

Figure 9. Schematic representations of force at ODH and at check strap

The door opening effort about the handle due to the check arm load can be calculated using the moment equilibrium diagram about the hinge axis. 
$\mathrm{Fh}=$ Operating force at Outer door handle to overcome check strap resistance

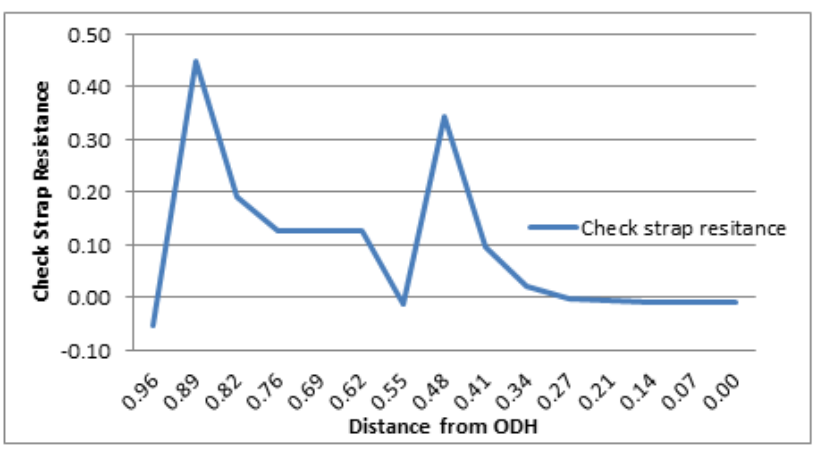

Figure 10. Operating force Vs. Distance from ODH

Figure 10 shows check strap operating force at each instance of door closure

Echk $=\mathrm{Fh} *$ Distance travelled at Outer door handle location

Echk $=$ Energy consumed by check; Energy consumed in check strap at $0.5 \mathrm{~m}$ open is 1.22 Joules.

Total energy consumed by fully open door is 5.66 Joules

...... 4.10

\subsection{Forces due Door Seals}

Figure 11 shows Door sealing section at roof and cantrail area. Figure shows two types of seal primary and secondary seal

\subsubsection{Primary sealing Force}

Sample calculation for seal: Figure 12 shows CLD curve of primary seal for section A-A Length of section A-A, $\mathrm{L}_{\mathrm{PSA}}=963 \mathrm{~mm}$ and Standard Seal compression $=8 \mathrm{~mm}$ Therefore, $\mathrm{E}_{\mathrm{PSA}}=$ Energy consumed by primary seal at section A-A for a length of $100 \mathrm{~mm}$,

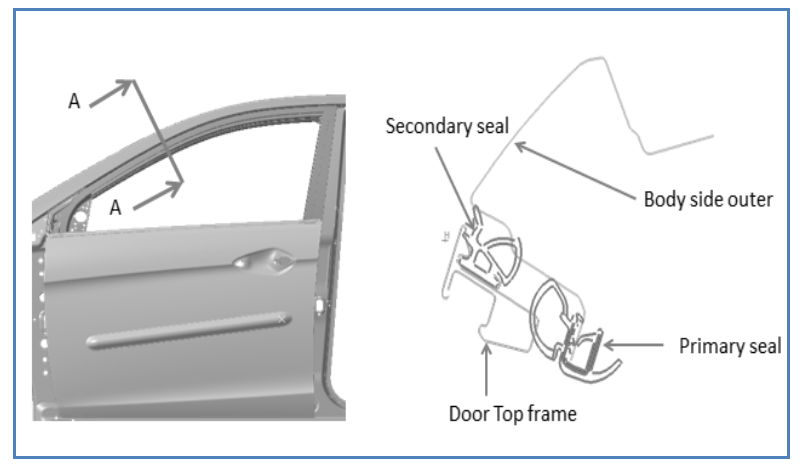

Figure 11. Door sealing section A-A at Roof

$\mathrm{E}_{\mathrm{PSA}}=$ Resistance force $\mathrm{X}$ Distance $=\mathrm{CLD} * 0.5 / 1000$ (For each $0.5 \mathrm{~mm}$ of travel of door of 100 $\mathrm{mm}$ seal) As sealing gap varies due to body variation, therefore in Worst condition, additional 2 $\mathrm{mm}$ compression of seals is considered and energy is calculated accordingly. Total Energy consumed by primary seal at Section A-A, 


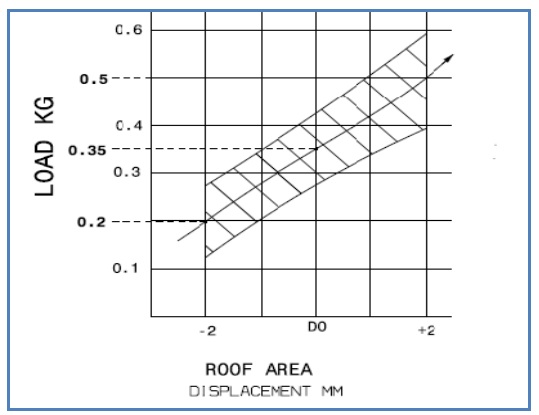

Figure 12. CLD at section A-A is $0.35 \mathrm{Kg} / 100 \mathrm{~mm}$

$\mathrm{TE}_{\mathrm{PSA}}=\mathrm{E}_{\mathrm{PSA}} * \mathrm{~L}_{\mathrm{SAA}}$

$\mathrm{L}_{\mathrm{SAA}}=$ Length of primary seal section A-A

Therefore, Total Median Energy at Section A-A $=\mathbf{0 . 2 7 5} \mathbf{J}$

Total Worst Energy at Section A-A $=0.393$ J. Similarly, Energy consumed at each section can be evaluated in this model and total maximum energy can be directly summed up.

Total Worst Energy of primary seal $\left(\mathrm{TE}_{\mathrm{PSA}}\right)=$

$0.393+0.106+0.256+0.056+0.149+0.197+0.042+0.106=\mathbf{1 . 0 3}$ Joules

\subsubsection{Secondary sealing Force}

Figure 13 shows CLD curve of secondary seal for section A-A

$\mathrm{E}_{\mathrm{SSA}}=$ Energy consumed by secondary seal at section A-A for a length of $100 \mathrm{~mm}$ can be evaluated same as primary seal

$\mathrm{E}_{\mathrm{SSA}}=$ Resistance force $*$ Distance; $\mathrm{E}_{\mathrm{SSA}}=\mathrm{CLD} * 0.5 / 1000$ (For each $0.5 \mathrm{~mm}$ of travel of door of $100 \mathrm{~mm}$ seal)

As sealing gap varies due to body variation Therefore in worst condition, additional $2 \mathrm{~mm}$ compression of seals is considered and energy is calculated accordingly.

Total Energy at Section E-E for secondary seal, $\mathrm{T} \mathrm{E}_{\mathrm{SS}}=\mathrm{E}_{\mathrm{SSA}} * \mathrm{~L}_{\mathrm{SAA}}$

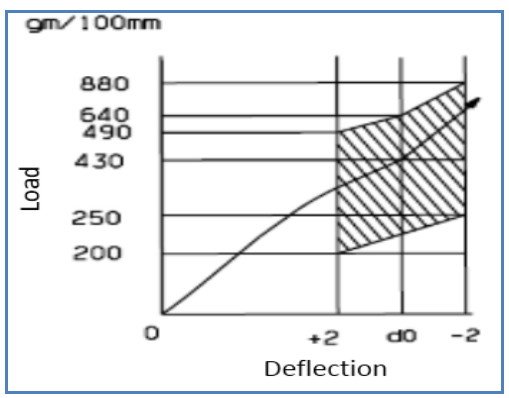

Figure 13. CLD at section A-A is $0.4 \mathrm{Kg} / 100 \mathrm{~mm}$

$\mathrm{L}_{\mathrm{SAA}}=$ Length of secondary seal section A-A

Therefore, Total Secondary Seal Median Energy at Section A-A $=0.091 \mathrm{~J}$

Total Secondary Seal Worst Energy at Section A- A $=0.195 \mathrm{~J}$ 
Similarly Energy consumed at each section can be evaluated in this model and total maximum energy can be directly summed up [5]

Total Worst Energy of Secondary seal $E_{S S}=0.186+0.195+0.034+0.040+0.118=0.573$ Joules

\subsection{Latching force}

Latch level operating forces are specified in drawing. Figure 14 shows schematic representation of latch and striker.

Latch operating force Primary $\left(\mathbf{F}_{\mathbf{L P})}=17 \mathrm{~N}\right.$; Latch operating force Secondary $\left(\mathbf{F}_{L S)}=15 \mathrm{~N}\right.$; Displacement of primary latch $\left(\mathbf{S}_{\boldsymbol{L P})}=21.5 \mathrm{~mm}\right.$; Displacement of secondary latch $(\mathbf{S L S})=10.5$ $\mathrm{mm}$

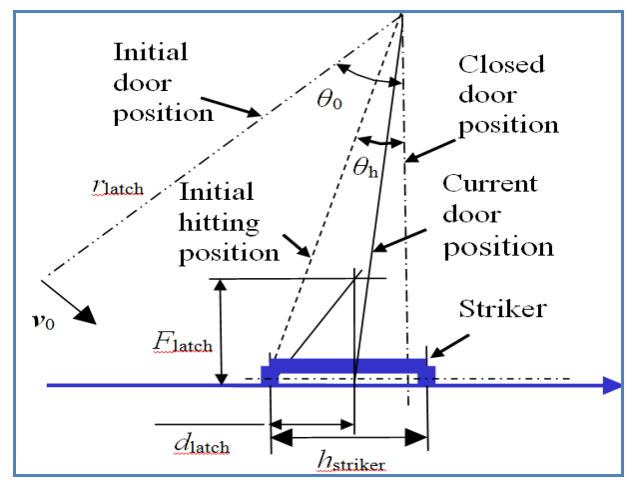

Figure 14. [4] Schematic representations of latch and striker

$\mathrm{E}_{\mathrm{L}}=$ Net energy consumed by latch $=0.523$ Joules

\subsection{Air binding effect}

Air binding force can be calculated by

$\int \mathrm{Fa}=\mathrm{Ds} * \Delta$ Ppeak $* \mathrm{C} \ldots \quad(\mathrm{C}=0.0208$ correction factor $)$

Where Ds $=S / V$ projected area of area enclosed by main seal $\left(\mathrm{m}^{2}\right)$ [1]. Figure 15 shows the rise in pressure as the door travels from full open to closed condition. Rise in pressure is at peak at the end of door stroke as shown

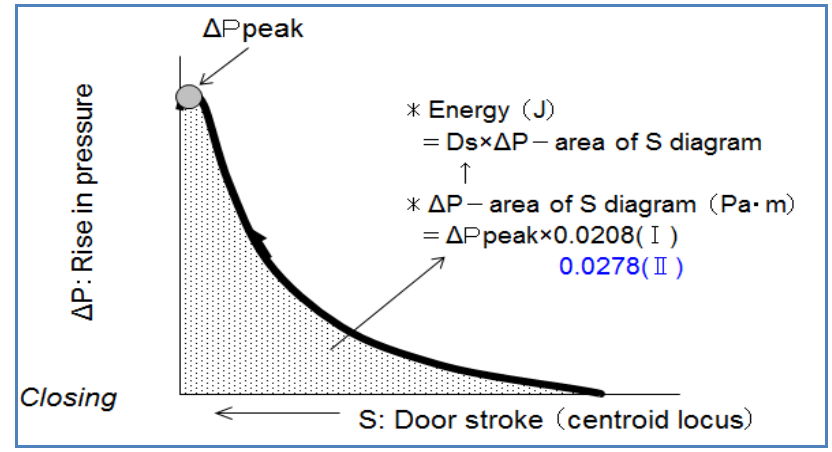

Figure 15. Pressure rise in cabin vs. Door stroke 
Ppeak= Maximum pressure measured at opening area.

$\mathrm{E}_{\mathrm{A}}=5.86$ Joules.

Hence total Energy consumed will be summation of energy consumed by each factor above from equation $4.7,4.10,4.11,4.12,4.13 \& 4.14$

$$
\begin{aligned}
& \mathrm{E}_{\text {Total }}=\mathrm{E}_{\mathrm{SCF}}+\mathrm{E}_{\text {chk }}+\mathrm{E}_{\mathrm{L}+} \mathrm{E}_{\mathrm{PS}}+\mathrm{E}_{\mathrm{SS}}+\mathrm{E}_{\mathrm{A}} \\
& \mathrm{E}_{\text {Total }}=-0.07+1.22+0.523+1.3+0.573+5.86=9.406 \text { Joules } \\
& \mathrm{E}=1 / 2 \times \mathrm{I} \times \omega 2 \\
& \omega=\sqrt{ }(2 \times \mathrm{E} / \mathrm{I}) \\
& \mathrm{V}=\omega \times \mathrm{R}
\end{aligned}
$$

Existing Design Velocity $=1.10 \mathrm{~m} / \mathrm{s}$

Therefore door closing velocity in above condition from numerical analysis is $1.1 \mathrm{~m} / \mathrm{s}$

\section{Estimation Of Door Closing Velocity In Modified Design}

Certainly the calculated velocity was higher than the benchmark values and Target set by PAT (Performance Attribute Target) team. Basic design modifications were required in some of the above factors for reducing the door closing velocity.

Following are the factors which were redesigned and fine-tuned to achieve the target.

\subsection{Hinge Friction}

Frictional resistance between hinge leaf and hinge pin is reduced by modifying the tolerances and adding anti-frictional bushes. Hinge Frictional Force $\left(\mathrm{F}_{\mathrm{HF}}\right)=1.83 \mathrm{~N}$

\subsection{Hinge Inclination angle}

Lower hinge point is modified by considering packaging limitation for dipper forward and inward angles which will assist in self-closing

Forward/ Rearward angle " $\beta$ " $=-2.58^{\circ}$; Inward / Outward angle " $\alpha$ " $=3.18^{\circ}$

Therefore energy due to Hinge axis inclination, weight and hinge friction $=-1.70$ Joules

\subsection{Secondary Seal modification}

Figure 16 shows comparison of existing seal and modified seal. The bulb type seal was modified to leap type as shown. 
International Journal on Cybernetics \& Informatics (IJCI) Vol. 4, No. 2, April 2015

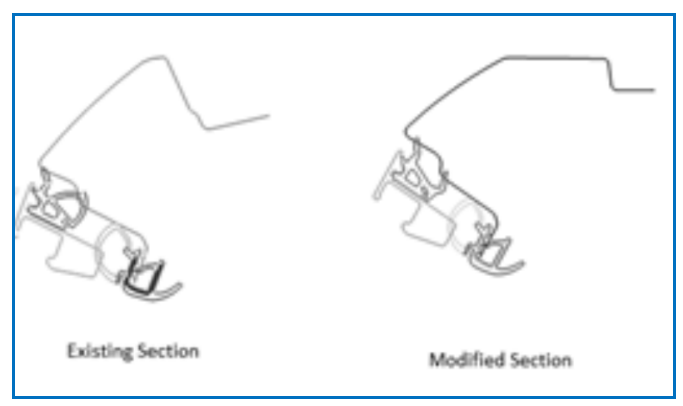

Figure 16. Modified secondary seal

Total Worst Energy of modified Secondary seal $=0.445 \mathrm{~J}$

\subsection{Energy consumed due to modified Check strap}

Energy consumed in modified check strap at $0.55 \mathrm{~m}$ open is 1.05 Joules

\subsection{Energy consumed by modified Latch}

Latch operating force Primary $\left(\mathrm{F}_{L P}\right)=15 \mathrm{~N}$; Latch operating force Secondary $\left(\mathrm{F}_{L S)}=12 \mathrm{~N}\right.$ $\mathrm{E}_{\mathrm{L}}=0.45$ Joules

\subsection{Total Modified Energy}

Hence total Energy consumed will be summation of energy consumed by each factor above

$\mathrm{E}_{\mathrm{Total}}=\mathrm{E}_{\mathrm{SCF}}+\mathrm{E}_{\mathrm{chk}}+\mathrm{E}_{\mathrm{L}+} \mathrm{E}_{\mathrm{PS}}+\mathrm{E}_{\mathrm{SS}}+\mathrm{E}_{\mathrm{A}}$

$\mathrm{E}_{\text {Total }}=-1.7+1.05+1.05+0.445+0.3+5.83=7.37$ Joules

Velocity $=0.89 \mathrm{~m} / \mathrm{s}$

Therefore door closing velocity in above condition from numerical analysis is $\mathbf{0 . 8 9} \mathbf{~ m} / \mathbf{s}$. Table 2 shows numerical analysed Energy consumed by each parameter in existing and modified door

Table No. 2. Energy comparison from each aggregate before and after modifications

\begin{tabular}{|l|l|l|}
\hline Parameters & $\begin{array}{l}\text { Existing door } \\
\text { Closing } \\
\text { (Joules) }\end{array}$ & $\begin{array}{l}\text { Improved Door } \\
\text { Closing energy } \\
\text { (Joules) }\end{array}$ \\
\hline Self-closing Energy & -0.07 & -1.7 \\
\hline Check Strap & 1.22 & 1.05 \\
\hline Primary Seal & 1.3 & 1.3 \\
\hline Secondary Seal & 0.573 & 0.445 \\
\hline Latch & 0.523 & 0.3 \\
\hline Air Bine Energy & 5.86 & 5.86 \\
\hline Total door closing energy & 9.406 & 7.37 \\
\hline
\end{tabular}




\section{Physical Test}

In order to have a direct measurement of the overall closing performance of a car's door .The Velocity gauge was used on the test vehicle, and is briefly described in this section. The door unit, shown in Figure 17 is mounted on the door to be tested through suction cups and contains the majority of the sensors of the System. This unit needs to be parallel to the floor and is placed at the height corresponding to the latching system of the door and the striker on the car body.

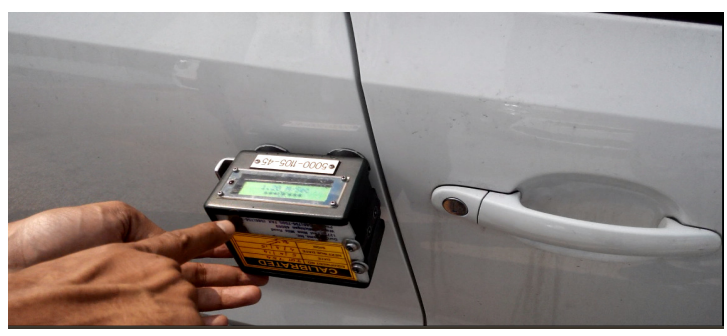

Figure 17. Velocity measuring gauge

The unit is placed on rear door by vacuum cups the other measuring sensors should not exceed more than $10 \mathrm{~mm}$ from the hemming edge of the door unit is placed. A display screen is given at the top which directly shows the reading of door closing velocity. The gauge is battery operated and cane be used independently in outdoor fields. The gauge is calibrated periodically to maintain its consistency and accuracy.

The door is shut from the fully open position to the latched position by manually applying force at door outer handle area. The complete closure of the door will be perceived by checking the flushness of the door physically. The velocity reading will be observed on the gauge which is set to read the velocity. To get minimum door closing velocity the procedure is repeated by optimizing the effort at each time of door one after the other.

\section{RESULTS AND DISCUSSION}

After all iterations in calculations and corresponding modifications in design, following table no. 3 shows physical readings observed for a sample size of 5 vehicles.

Table 3 Physical test for a sample of five vehicles

\begin{tabular}{|l|l|l|l|}
\hline $\begin{array}{l}\text { Sr. } \\
\text { No. }\end{array}$ & Make & $\begin{array}{l}\text { Front door LH closing } \\
\text { velocity in } \mathrm{m} / \mathrm{s}\end{array}$ & $\begin{array}{l}\text { Front door LH closing } \\
\text { velocity in m/s }\end{array}$ \\
\hline 1 & $\begin{array}{l}\text { OEM } \\
\text { Vehicle 1 }\end{array}$ & 0.94 & 0.95 \\
\hline 2 & $\begin{array}{l}\text { OEM } \\
\text { Vehicle 2 }\end{array}$ & 0.95 & 0.85 \\
\hline 3 & $\begin{array}{l}\text { OEM } \\
\text { Vehicle 3 }\end{array}$ & 0.95 & 0.98 \\
\hline 4 & $\begin{array}{l}\text { OEM } \\
\text { Vehicle 4 }\end{array}$ & 0.88 & 0.96 \\
\hline 5 & $\begin{array}{l}\text { OEM } \\
\text { Vehicle 5 }\end{array}$ & 0.94 & 0.86 \\
\hline
\end{tabular}

The average door closing velocity obtained was $0.926 \mathrm{~m} / \mathrm{s}$ and average door closing velocity of existing model was $1.2 \mathrm{~m} / \mathrm{s}$, which were $0.274 \mathrm{~m} / \mathrm{s}$ lower than the existing model thus achieving 
an overall benefit of $22.8 \%$. Maximum error of $10 \%$ was observed in mathematical and physical model. Further it was observed that tweaking with hinge axis and sealing gives the maximum benefit. Hence it can be concluded that for a new development, optimization of hard points in the initial design stage would be most beneficial. However for an existing model, seal, latch and check strap modification as a running change will be the most optimum solution with minimal cost impact.

\section{Conclusion}

In this paper, modifications in the door systems are proposed, which helps in reduction of door closing velocity. The parameters like hinge friction, hinge axis inclination, sealing, latch and air bind effect which affects door closing effort are analysed. A mathematical model is prepared to evaluate door closing velocity through calculating energy contribution method by each parameter. Door closing velocity in partially open condition i.e. from first check position is evaluated. Door closing velocity is calculated for the existing model and to improve the existing scenario design modifications are proposed in the hinge axis inclination, sealing, check strap resistance reduction, secondary seal, and latch operating efforts. These design modifications after implementation have shown reduction in door closing velocity by $22.8 \%$. Physical validation is also done and results are found to be in tandem with the theoretical calculation and physical test.

\section{ACKNOWLEDGEMENTS}

I wish to express our profound thanks to my project guide, Prof. Dr. A.M. Badadhe for his meticulous planning, the valuable time that he spent with me, discussing my ideas and helping me jump over any hurdles that would come our way. I would also like to express my sincerest gratitude to my guide for helping me carry out literature survey, research and comparative study which have led to my completion of paper

I am also grateful to the Head of Department, Mechanical Engineering at Rajarshi Shahu College of Engineering, Dr. A.A.Pawar for giving valuable attention and experience that has helped me in achieving my goals.

I also want to thank our respected principal Dr. D.S.Bormane for providing me with the basic infrastructure and other facilities.

This acknowledgement would remain incomplete if I do not thank departmental staff of Rajarshi Shahu College of Engineering, Tathawade for their ever helpful attitude towards making this project, a great success.

\section{REFERNCES}

[1] Y. Nagayama and R. Fujihara NissanMotor Co., Ltd.(1982), “A Consideration of Vehicle's Door Shutting Performance", SAE 810101

[2] Raviraj Nayak and Kee Im General Motors (2003), "Optimisation of Side Swing Door Closing Effort", SAE 2003- 01 - 0871

[3] Vitor de Uzeda Sandrini, Mauricio Massarotti, Marco Maia, Emilio Sakaguti and Paulo Mendonça General Motors do Brasil,(2008) "A case-study about side door closing effort", SAE - 2008-36-0154

[4] Jing Li and Zissimos P. Mourelatos Oakland University, (2009), "Prediction of Automotive Side Swing Door Closing Effort", SAE- 2009-01-0084

[5] Fernando Pereira and Gilbero De Souza, (2010) "Automotive Door closing effort study", SAE 2010-36-0394 